\title{
The Mechanical Behaviour during Multiple Injections and its Influence on Fracture Network
}

\section{Li-Feng YANG ${ }^{1, \text { a }}$, Yu-Zhang LIU ${ }^{1,2}$, Yun-Hong DING ${ }^{1,2}$, Yong-Hui WANG ${ }^{1,2}$ and Xiao-Sen SHANG ${ }^{1,2}$}

\author{
${ }^{1}$ China National Petroleum Corporation the Key Laboratory of Reservoir Stimulation, \\ Langfang, China \\ 2Langfang Branch of Petroleum Exploration and Development of Research Institute, \\ Langfang, China
}

Keywords: Multiple Injections, Fracturing, Shale gas, Fracture network.

\begin{abstract}
Many cases show that multiple injections fracturing serves as an effective method to increase the probability of creating complex fracture network for shale gas reservoirs. However, its mechanism is unclear. This paper, therefore, intends to use numerical simulation and theoretical models to explore this mechanism. Results indicate that the liquid fluid loss and friction along fractures act as catalysts to a large pressure drop between the initiation of fractures and the fractures tip during injection. But friction disappears when this injection terminates, and the fluid pressure decreases at the debut of fractures and increases at the fractures tips. Then the stress field changes synchronically. The probability of the extension and reorientation of fracture tip and the initiation and reorientation of weak point on the fracture surface may be multiplied. During the re-injection after a period of shut-in, the opened factures or weak points can easily propagate new fractures and does not need to overcome the resistance of the tensile strength or cohesion. Then larger volume of fracture network and more fractures can be created by multiple injections. Micro-seismic monitoring results verify the validity of the theoretical analysis and effectiveness of the method of multiple injections fracturing.
\end{abstract}

\section{Introduction}

Creating larger volumes and complex fracture network is a main goal of hydraulic fracturing for shale gas. One important means of forming a complex artificial fracture network is increasing net pressure. Of late, many studies have been made to create more complex fracture network for shale gas by adding temporary plugging[1-5] to increase net pressure in fractures or by reducing the spacing between fractures [6-10] to change the local stress. However, these methods are not costeffective.

Kiel and Abhijeet Inamdar[11-13] pointed out multiple injection hydraulic fracturing can create more complex fracture network for reservoir with abundant natural fractures(they call it relax-frac). They infer that multiple injections can change the stress state of the reservoir, in order to achieve more complicated fracture network. But they failed to do any detailed analysis of the mechanism.

Their method was also reported in China. Fluid and proppant was pumped into reservoir two or more times within a short time [14- 19]. However these reports lay more emphasis on the times. The success of this method is dependent on proppant distribution and stress change.

A traditional model was used to optimize shut-in time between secondary and primary fracturing by He Tao and etc. [20]. They proposed formation pressure stabilization time between the first and secondary fracturing is a reasonable shut-in time. There are no reports on effect of the fluid pressure redistribution in fractures on fracture shape and stress field during hydraulic fracturing shut-in time.

This paper deals with the mechanical behaviour between fluid and rock during shut-in time and the mechanism of multiple injection operations to increase the complexity of the fracture network. The stress field and pressure in fractures were analysed during injection and shut-in time. The analysis shows that the pressure redistribution in fractures and stress redistribution will increase the 
possibility of extending the fractures tip as well as opening the weak points on the fractures walls, increasing the fractures height along the extending direction.

The mechanical behaviour between fluid and rock during injection and shut-in time was used by the multiple injections fracturing to create more fractures. It is a cheap and effective method without needing more fluid and more complex operation.

\section{Pressure Distribution during Injection and Shut-in}

\section{Pressure Distribution during Injection}

In addition to the wellbore pressure drop, the pressure drop $\Delta \mathrm{P}_{\mathrm{f}}$ associated with the crack can be divided into two areas during injection. The first is near the well, mainly caused by friction completion, such as casing perforations friction caused by perforation completion(Fig.1, $\mathrm{P}_{\mathrm{wf}}-$ $\left.\mathrm{P}_{\mathrm{t} 0}=\Delta \mathrm{P}_{\mathrm{hole}}\right)$. The second pressure drop area is from two parts. It comes from the friction between fracture surface and fracturing fluid druing flow.It is recorded as $\Delta \mathrm{P}_{\mathrm{f} 1}$.It is also caused by fluid loss. It is recorded as $\Delta \mathrm{P}_{2}$.

$$
\Delta \mathrm{P}_{\mathrm{f}}=\mathrm{P}_{\mathrm{tL}}-\mathrm{P}_{\mathrm{t} 0}=\Delta \mathrm{P}_{\mathrm{f} 1}+\Delta \mathrm{P} 2
$$

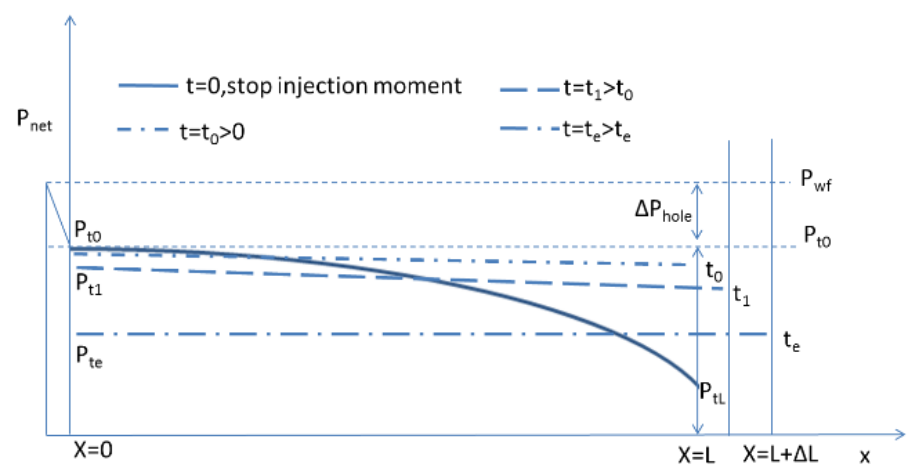

Fig. 1.The schematic diagram of net pressure distribution along the fracture extension direction during shut-in.

For example, a full three-dimensional fracture propagation model was used to calculate the pressure distribution during shut-in for CASE1 well in WY gas reservoir. Two types of fluid were used, one is slick water with low viscosity, the other is x-link with higher viscosity. The reservoir depth is $3000 \sim 3010 \mathrm{~m}$, stress gradient is $0.015 \mathrm{MPa} / \mathrm{m}$, pore pressure coefficient is 1.0 , rock young's modulus is $26000 \mathrm{MPa}$, the poisson's ratio is 0.25 , permeability is $0.1 \mathrm{mD}$, porosity is 0.1 , rock fracture toughness is $2.2 \mathrm{MP} \cdot \mathrm{m}^{1 / 2}$. Two horizontal principal stress differences are $3 \mathrm{MPa}$, slick water viscosity is $2.0 \mathrm{mPa} \cdot \mathrm{s}$, $\mathrm{x}$-link viscosity is $30.0 \mathrm{mPa} \cdot \mathrm{s}$, injection rate $14 \mathrm{~m}^{3} / \mathrm{min}$, the injection fluid volume, $180 \mathrm{~m}^{3}$.

Simulation results show that there is big net pressure difference between fracture entrance and fracture tip(Figure 2).Different fluid viscosities get different pressure. The pressure difference $\Delta \mathrm{P}_{\mathrm{f}}$ is about $3 \mathrm{MPa}$ for slick water and nearly $9 \mathrm{MPa}$ for $\mathrm{x}$-link.

\section{Pressure Redistribution during Shut-In}

\section{Three Stages during Shut-In for Fractures}

It can be divided into three main stages according to fluid flow state and change of fracture shape during shut-in time. The first is unstable changing stage before fracture closure. The second is fracture stable closure stage. The third is after fracture closure stage. 


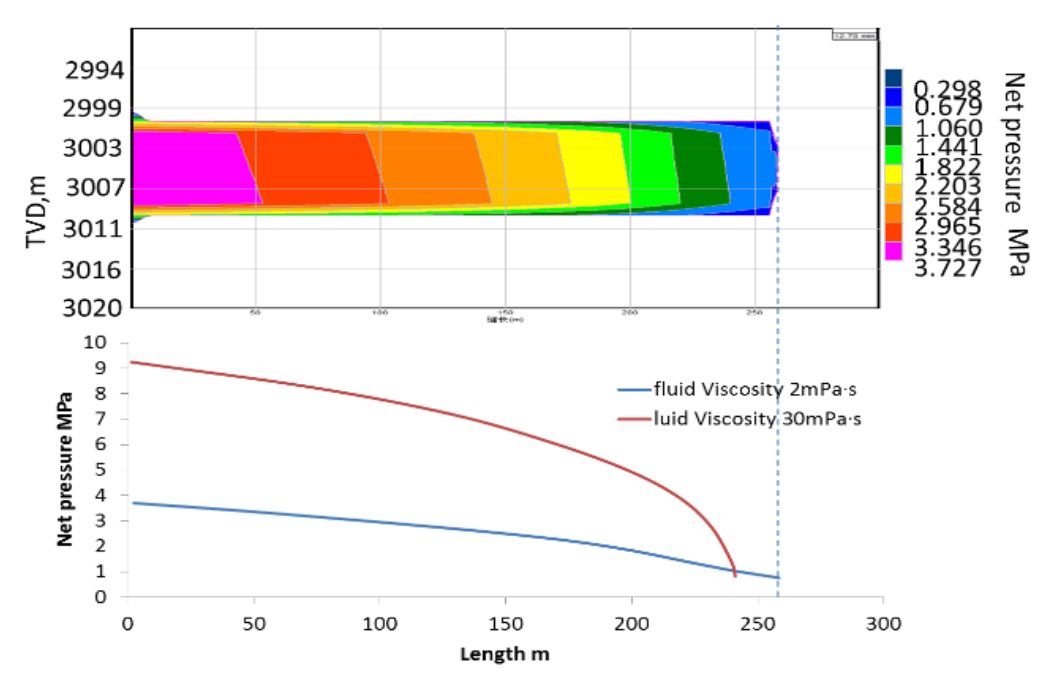

Fig. 2. Net pressure distribution along the fracture extension direction when stop injection moment for case 1

(1)Unstable stage before the fracture closure . During this stage, the fluid continues to flow at very low rate. Friction between fuild and fracture wall is approximately $0 \mathrm{MPa}$. It can also be divided into two stages based on the state of the fluid flow inside the fracture, one is water hammer stage and the other is stable freewheeling stage.

Water hammer stage : The dramatic pressure change was caused by the instantaneous shut-in, the fluid pressure alternately went up and down dramatically in pipes and fractures. Fluid flow still goes on during this stage.

Stable freewheeling stage: The bottom hole pressure shows sustained reductions and no fluctuations. However, due to big pressure difference between the fracture tip and fracuture start during injection, the pressure tends to lead to a state of equilibrium after injection is stopped. The fracture is in an unstable stage. Druing this satge, the fluid still flows within the fracture.

(2)The fracture stable closure stage. There is approximately same pressure along fracutre and no fracutre extending or initiation. Fracutre starts closing during this stage.

(3)After fracture closure stage: Fracture closes completely and fluid loss continues.

\section{Pressure Distribution during Stable Freewheeling Stage}

Here the pressure distribution during stable freewheeling stage is discussed as the mechanical behaviour between fluid and rock during this stage is more important and complex than other stages. Before shut-in, the fluid pressure distribution has a gradient from fracture start to fracture $\operatorname{tip}\left(\mathrm{P}_{\mathrm{t} 0} \sim \mathrm{P}_{\mathrm{tL}}\right.$, Figure 1. Although the fracturing fluid still flows after injection is stopped during unstable changing stage, the rate is much less than injection. Therefore, the perforations friction and the bending fracture friction can be neglected. At this stage the fluid pressure will tend to balance for a very short time.The fluid pressure will reduce at the fracture entrance and increase at the tip(Figure 1, thus as the $t_{0}, t_{1}$, te time corresponding pressure curve. As the pressure wave propagation velocity in the liquid is very fast $($ about $1500 \mathrm{~m} / \mathrm{s}$, the fluid pressure from the fracture entrance to the tip will reach the same with and little pressure drop just as Figure 1 shows (from $\mathrm{Pt} 0$ reduced to $\mathrm{P}_{\mathrm{t} 1}$ ). The pressure re-distribution will lead to fracture extending continually or new fracture being created until the fluid pressure drops to a critical pressure Pte[21]. 


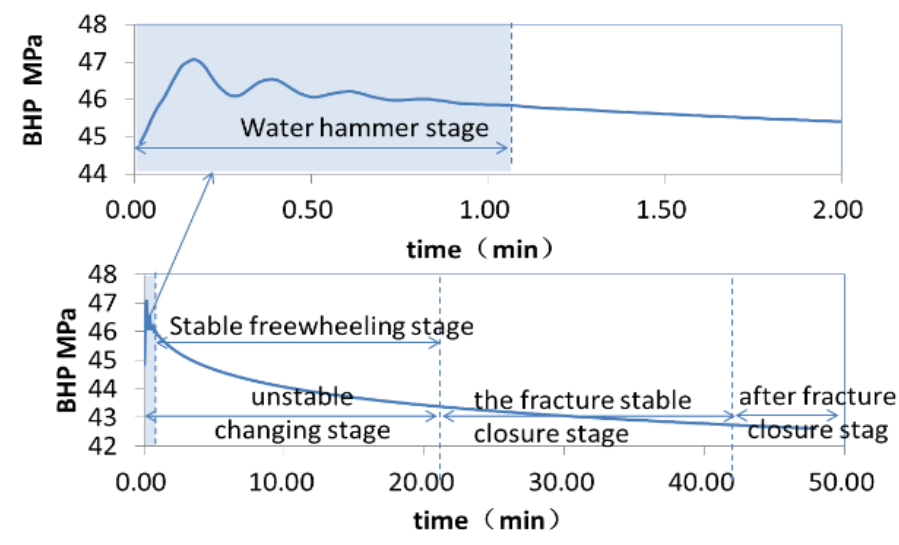

Fig. 3. The fluid pressure inside fracture distribution during shut-in in Well B

\section{The Stress Field Changing during First Injection and Shut-in}

\section{Induced Stress Calculation Model}

The stresses will change significantly during injection. They come from three parts. The first is from the fracture. The second from pore pressure. The third from temperature. For shale gas reservoir, the permeability is so low(Nano Darcy) that the reservoir temperature and reservoir pressure propagation distance is shorter in the vertical fracture orientation. The change of maximum and minimum principal stress caused by temperature and pore pressure increase on the same level for shale gas reservoir and it can be neglected [21].

Induced stresses caused by fracture can be calculated by the following equation (2) (7).

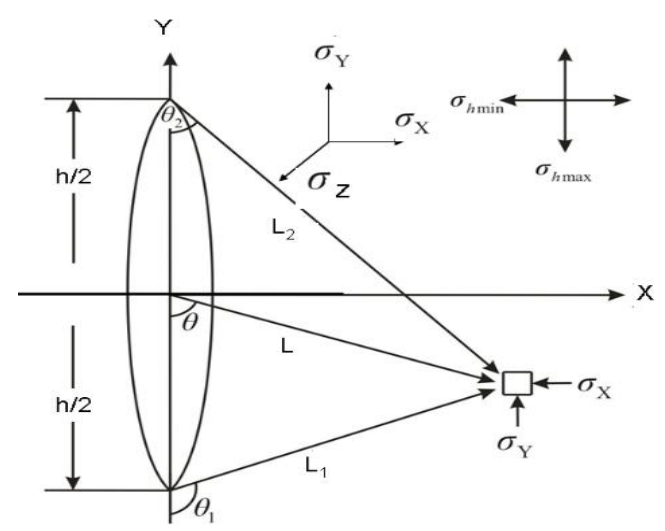

Fig. 4. The stress distribution schematic of artificial fracture height direction cross-section

$$
\begin{gathered}
\sigma_{\mathrm{x}}=p_{\text {net }} \frac{L}{c}\left(\frac{c^{2}}{L_{1} L_{2}}\right)^{\frac{3}{2}} \sin \theta \sin \frac{3}{2}\left(\theta_{1}+\theta_{2}\right) \\
+p_{\text {net }}\left[\frac{L}{\left(L_{1} L_{2}\right)^{\frac{1}{2}}} \cos \left(\theta-\frac{1}{2} \theta_{1}-\frac{1}{2} \theta_{2}\right)-1\right] \\
\sigma_{\mathrm{z}}=-p_{\text {net }} \frac{L}{c}\left(\frac{c^{2}}{L_{1} L_{2}}\right)^{\frac{3}{2}} \sin \theta \sin \frac{3}{2}\left(\theta_{1}+\theta_{2}\right) \\
+p_{\text {nec }}\left[\frac{L}{\left(L_{1} L_{2}\right)^{\frac{1}{2}}} \cos \left(\theta-\frac{1}{2} \theta_{1}-\frac{1}{2} \theta_{2}\right)-1\right] \\
\sigma_{\mathrm{y}}=v\left(\sigma_{\mathrm{x}}+\sigma_{\mathrm{z}}\right)
\end{gathered}
$$




$$
\begin{aligned}
\tau_{\mathrm{xz}}=p_{\text {net }} \frac{L}{c}\left(\frac{c^{2}}{L_{1} L_{2}}\right)^{\frac{3}{2}} \sin \theta \cos \frac{3}{2}\left(\theta_{1}+\theta_{2}\right) \\
\left\{\begin{array}{l}
L=\sqrt{x^{2}+y^{2}} \\
L_{1}=\sqrt{x^{2}+(y+c)^{2}} \\
L_{2}=\sqrt{x^{2}+(y-c)^{2}}
\end{array}\right. \\
\left\{\begin{array}{l}
\theta=\tan ^{-1}\left(-\frac{x}{y}\right) \\
\theta_{1}=\tan ^{-1}\left(-\frac{x}{y+c}\right) \\
\theta_{2}=\tan ^{-1}\left(\frac{x}{c-y}\right)
\end{array}\right.
\end{aligned}
$$

$x, y$ are coordinates of a point, $\mathrm{m} ; L$ is the distance $\operatorname{from}(x, y) \operatorname{to}(0,0), \mathrm{m} ; L_{1}$ is the distance from $(\mathrm{x}, \mathrm{y})$ to $(0, h / 2), \mathrm{m} ; L_{2}$ is the distance to $(0,-h / 2), \mathrm{m} ; \theta, \theta_{1}, \theta_{2}$ is $L, L_{1}, L_{2}$ line and $\mathrm{Y}$-axis angle respectively, (if the $\theta, \theta_{1}, \theta_{2}$ is negative then the angle can be used $\theta+180^{\circ}, \theta_{1}+180^{\circ}$ and $\theta_{2}+180^{\circ}$ to replace respectively); $H$ is fracture height, $\mathrm{m} ; P_{\text {net }}$ the fracture net pressure. it equal to the difference between the pressure in the fracture and local minimum principal stress, $\mathrm{Pa} ; \sigma_{\mathrm{x}}, \sigma_{\mathrm{y}}, \sigma_{\mathrm{z}}$ is principal stress in $x, y, z$ directions respectively, $\mathrm{Pa} ; v$ is Poisson's ratio, dimensionless; $\tau_{\mathrm{xz}}$ is shear in $\mathrm{z}$ direction. it is perpendicular to the xy-planefor, $\mathrm{Pa} ; c$ semi-fracture height, equal to $h / 2, \mathrm{~m}$.

\section{The Stress Changing on Fracture Surface at the Moment of First Injection Stopping}

The stresses change along fracture on the surface is calculated by equations (2) (7) for CASE1 well in WY gas reservoir when first injection is stopped (Figure 5). $\Delta \sigma_{\mathrm{hmax}}$ is induced stress in maximum principal stress direction. $\Delta \sigma_{\mathrm{hmin}}$ is induced stress in minimum principal stress direction. They are caused by $\mathrm{P}_{\text {net. }} \sigma_{\text {hmax }}^{\prime}$ and $\sigma_{\text {hmin }}^{\prime}$ are maximum and minimum principal stress when the induced stresses taken into account.

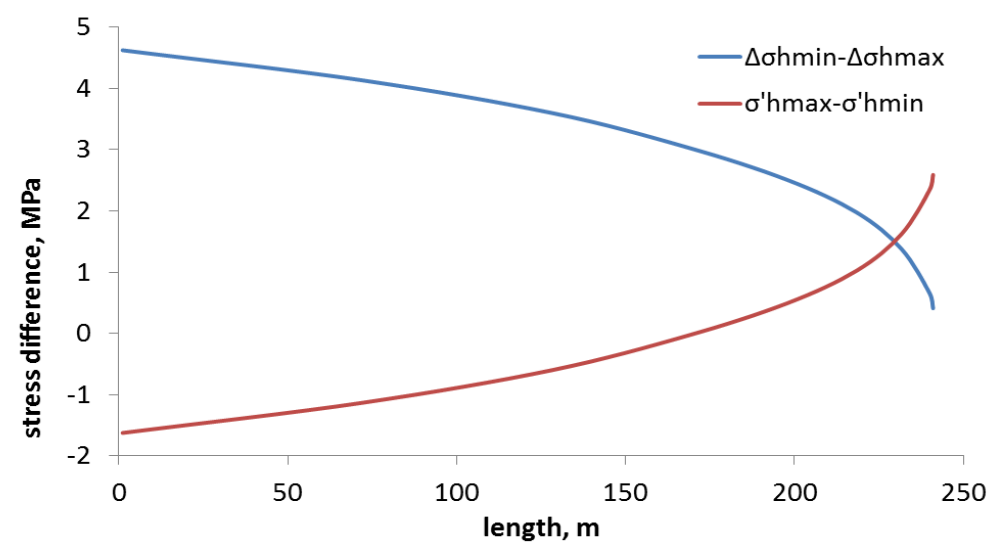

Fig. 5. The change of maximum and minimum principal stress difference along the fracture at the moment of instantaneous stop in the first injection

\section{The Stress Changing on Fracture Surface during Shut-in}

Simulation results show that the injection induced stress will lead to the difference between maximum and minimum principal stress $\sigma_{\text {hmax }}^{\prime}-\sigma_{\text {hmin }}^{\prime}$ is smaller than original (Figure 6). As time increases, the difference becomes smaller and smaller druing shut-in.

At the begining of shut-in, the fluid pressure tends to balance. This balancing process will lead to the redistribution of net pressure and the redistribution of stresses (Figure 6, just as te, $\mathrm{t}_{1}, \mathrm{t}_{0}$ corresponding pressure curve). 


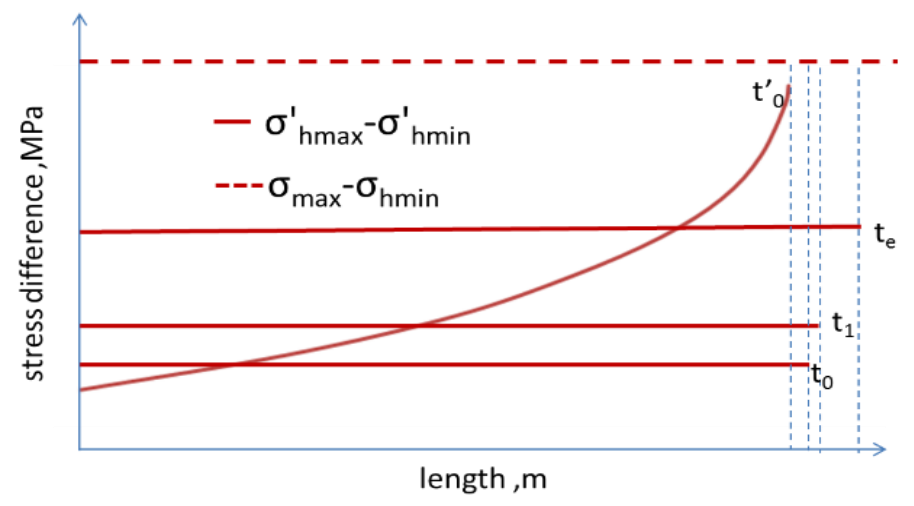

Fig. 6. The changing of maximum and minimum principal stress difference along the fracture druing shut-in

The Feasibility of Multi-Injection to Improve the Quality of Fracture Network for Shale Gas Reservoir

Breakdown conditions are the judging key for shale gas reservoir whether the fractures can become network or not. For the hydraulic fracturing process, there are two typical forms of failure, tensile failure and shear failure.

\section{The Judging Conditions of Tensile Failure and Shear Failure}

According to Perkins[23], the fracture will initiate and propagate when the net pressure is bigger than rock tensile strength druing hydraulic fracturing.

$$
P_{n e t} \geq \sigma T
$$

In maximum principal stress direction, the fracture tip initiation and propagation criteria can be described as follows.

$$
P \geq \sigma_{\text {hmin }}+\sigma_{T}
$$

Howerer, in minimum principal stress direction the rock damage criteria can be described as follows.

$$
P \geq \sigma h \max +\sigma_{T}
$$

To shear failure, the shear stress must overcome the rock shear strength (also known as cohesion) and friction [24].

$$
\tau=C+\mu \cdot \sigma
$$

tis shear stress, $\mathrm{MPa}$; $\mu$ is internal friction coefficient of rocks; $\mathrm{C}$ is inherent shear strength, $\mathrm{MPa}$; бis failure surface normal stress .

To shear failure, the shear stress must overcome the rock shear strength (also known as cohesion) and friction [24].

\section{Analysis of Multi-Injection to Increase the Probability of Creating or Improving the Quality of the Fracture Network}

Multi-injection can increase the probability of creating or improving the quality of the fracture network. The reasons are as follows:

First of all, first injection will change the maximum and minimum principal stress difference(Figure 5). The local maximum and minimum principal stress difference will become smaller than original during shut-in. It will also become smaller than injection period, especially far away from the fracture entrance. When next injection is executed, new fractures may initiate and propagate across the existing fractures surface. New fractures and existing fractures can form fracture network. 
Secondly, multi-injection can increase the chances of rock tensile or shear failure.

The fluid pressure will redistribute after first injection, especially far away from fracture entrance. The larger the net pressure obtained by the injection, the greater the net pressure increased far away from fracture entrance during shut-in. This will improve rock damage possibility according to equations (8) (11). Just as the example in Figure 2, as the net pressure is smaller than $3 \mathrm{MPa}$ (maximum and minimum principal stress difference) from $90 \mathrm{~m}$ to $260 \mathrm{~m}$ (slick water) or from $230 \mathrm{~m}$ to $240 \mathrm{~m}$ (x-link), new fracture can not be created along existing fracture. However, when injection is stopped, the net pressure can become larger than $3 \mathrm{MPa}$ from $90 \mathrm{~m}$ to $260 \mathrm{~m}$ (slick water) or from $230 \mathrm{~m}$ to $240 \mathrm{~m}$ (x-link) and new fractures may be created in these ranges.

Thirdly, if new fractures has been created during shut-in, then it can be initiated and propagated easily when rock is damaged.The reason is that the new fracture does not need to overcome rock tensile strength $\sigma_{\mathrm{T}}$ or cohesion $\mathrm{C}$.

\section{Analysis of Micro Seismic Monitoring Results during Shut-in}

Abhijeet Inamdar and el. point out the micro-seismic data analysis shows that the micro-seismic events still occurred during shut-in at the Eagle Ford shale wells [12].The micro-seismic events can be increased by injection - shut-in - injection and the production can be increased too. This phenomenon also can be found when Sichuan Long ma xi shale gas was stimulated.(Figure 7 Figure 8).

One example $\mathrm{n}$ is the vertical well w2 stimulated by slick water and micro-seismic events. It shows that the fracture is single. During shut-in, micro-seismic events still occurred. During the second injection with pumping rate the same as first injection (about $15.9 \mathrm{~m}^{3} / \mathrm{min}$ ), the net pressure was almost the same. However, the micro-seismic events show that more and more fractures were created and fracture network formed (Figure 7).

Another example is the horizontal well Y stimulated by slick water. Multi-injection was used and the micro-seismic events showed that the fracture had changed propagation direction (Figure 8).

Micro-seismic events show that multi-injection can contribute to creating complex fracture network.

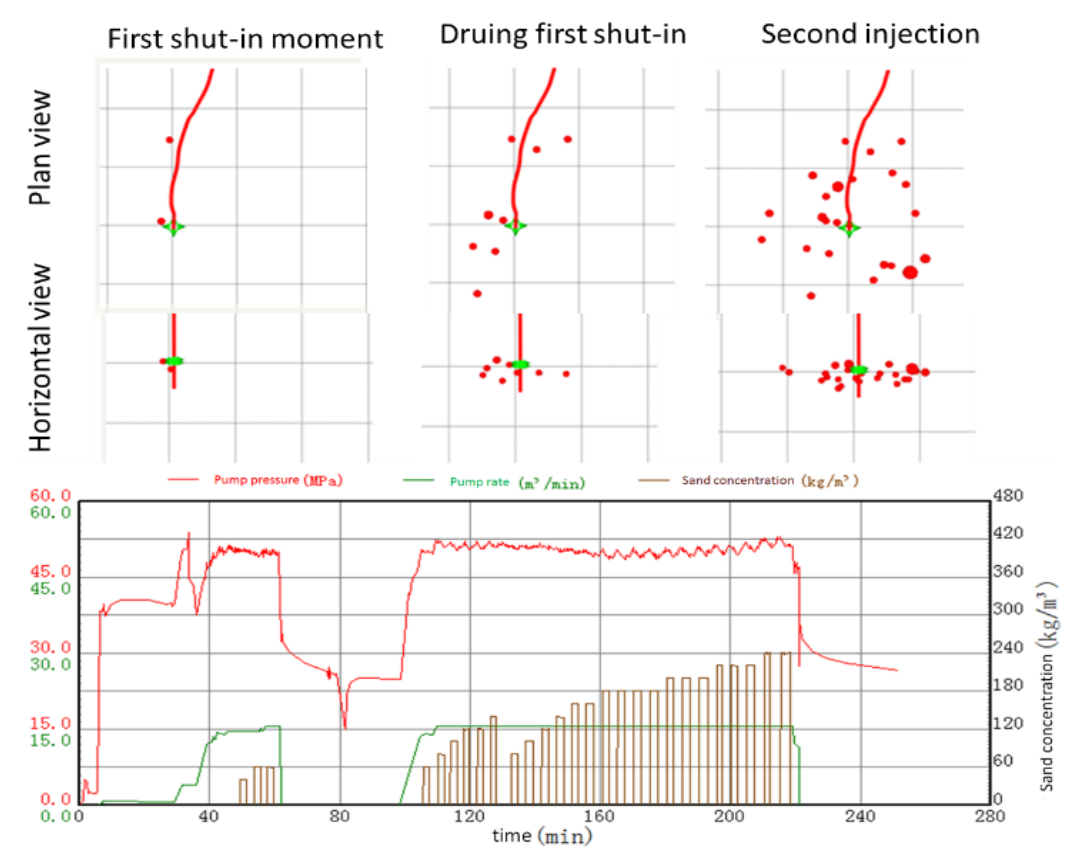

Fig. 7. Micro-seismic data and performance curve of the vertical well w2 during two injection times 


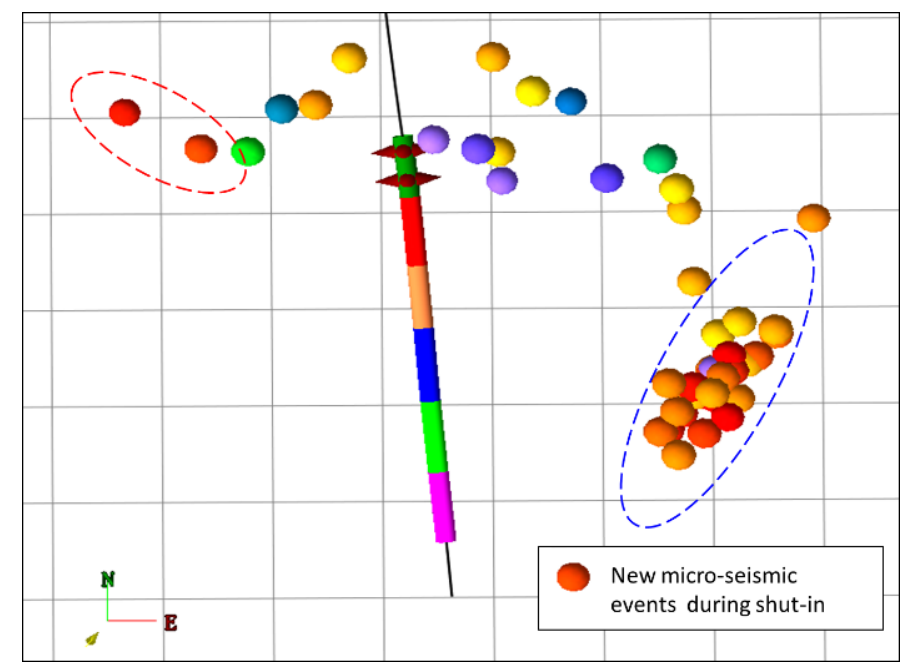

Fig. 8. Micro-seismic data of the the horizontal well Y during two injection times

\section{Conclusions}

1) There is big fluid pressure difference between fracture entrance and fracture tip during injection. The pressure will redistribute during shut-in. Injection and stopping can increase the pressure inside fracture, especially near fracture tip.

2) Maximum and minimum principal stress difference changed owing to multi-injection. This can increase the probability of rock tensile or shear failure.

3) If rock was damaged during injcetion or shut-in, then the fractures can be initiated and propagated easily during next injection.

4) Micro-seismic events show that mlti-injection can contribute to creating complex fracture network.Thisis a cheap method to create fracture network

\section{Acknowledgments}

This paper was support by the National Basic Research Program of China (no. 2013CB228004). We would like to thank Prof. ZHANG Jian-min, Zhejiang University and Prof. LIU Ming, Zhejiang University.

\section{References}

1. McCartney E. S., Kennedy, R.L.A Family of Unique Diverting Technologies Increases Unconventional Production and Recovery in Multiple Applications - Initial Fracturing,Refracturing, and Acidizing (C) //paper 179115-MS, presented at the SPE Hydraulic Fracturing Technology Conference, 9-11 February, The Woodlands, Texas, USA .DOI: http://dx.doi.org/10.2118/179115MS

2. Gary Rodvelt, Mian Ahmad, Austin Blake. Refracturing Early Marcellus Producers Accesses Additional Gas (C) //paper 177295-MS, presented at SPE Eastern Regional Meeting, 13-15 October, Morgantown, West Virginia, USA. DOI: http://dx.doi.org/10.2118/177295-MS

3. Zhao Xianzheng, and Li Yongjun, Cai Bo. Study of an Oil Soluble Diverting Agent for Hydraulic Fracturing Treatment in Tight Oil and Gas Reservoirs (C)// paper 178142-MS , presented at SPE/IADC Middle East Drilling Technology Conference and Exhibition, 26-28 January, Abu Dhabi, UAE .DOI: http://dx.doi.org/10.2118/178142-MS

4. Ahmed M. Gomaa, Andrea Nino-Penaloza, Dorianne Castillo, Elizabeth McCartney, and John Mayor. Experimental Investigation of Particulate Diverter Used to Enhance Fracture Complexity[C]// paper 178983-MS , presented at the SPE International Conference and Exhibition 
on Formation Damage Control, 24-26 February,Lafayette,Louisiana,USA. DOI: http://dx.doi.org/10.2118/178983-MS

5. Ahmed M. Gomaa, Hong Sun, Scott Nelson, Qi Qu, and Go Virgilio Boncan, Using Swelling Materials to Control Fracture Complexity: Experimental Study[C]//paper 174783-MS, presented at the SPE Annual Technical Conference and Exhibition, 28-30 September, Houston, Texas, USA.DOI: http://dx.doi.org/10.2118/174783-MS

6. Jo, Hyunil, Optimizing Fracture Spacing to Induce Complex Fractures in a Hydraulically Fractured Horizontal Wellbore [C]//paper 154930, presented at the Americas Unconventional Resources Conference, 5-7 June 2012,Pittsburgh, Pennsylvania, USA. DOI:http://dx.doi.org/10.2118/154930-MS

7. P.N. Mutalik and Bob Gibson, Williams Companies, Case History of Sequential and Simultaneous Fracturing of the Barnett Shale in Parker County[C]//paper 116124, presented at the 2008 SPE Annual Technical Conference and Exhibition, 21-24 September 2008,Denver, Colorado, USA. DOI: http://dx.doi.org/10.2118/116124-MS

8. Soliman Loyd East, David Adams, "Geomechanics Aspects of Multiple Fracturing of Horizontal and Vertical Wells”[J]. SPE Drilling \& Completion, 2008, 23(3): 217-228.

9. M.K. Fisher, J.R. Heinze, C.D. Harris B.M Davidson, C.A.Wright, and K.P. Dunn, Optimizing Horizontal Completion Techniques in the Barnett Shale Using Microseismic Fracture Mapping[C]//paper 90051, presented at the SPE Annual Technical Conference and Exhibition , 26 29 September 2004, Houston,Texas USA.DOI: http://dx.doi.org/10.2118/0305-0041-JPT

10. N.P. Roussel, M.M. Sharma, Optimizing Fracture Spacing and Sequencing in Horizontal Well Fracturing[C]//paper 127986, presented at the SPE International Symposium and Exhibition on Formation Damage Control,10-12 February 2010,Lafayette, Louisiana, USA.DOI: http://dx.doi.org/10.2118/127986-MS

11. Kiel, O.M,The Kiel Process - Reservoir Stimulation by Dendritic Fracturing. Paper SPE 6984 1977

12. Abhijeet Inamdar, Raj Malpani, Keith Atwood, Keith Brook, and Abdunnaser Erwemi, and Tolu Ogundare, Dave Purcell, Evaluation of Stimulation Techniques Using Microseismic Mapping in the Eagle Ford Shale[C]//paper 136873,presented at the SPE Tight Gas Completions Conference , 2-3 November 2010,San Antonio, Texas, USA DOI: http://dx.doi.org/10.2118/136873-MS

13. Liu Lifeng, Zhang Shicheng, Net fracturing by changing the surrounding in-situ stress in shale reservoirs, Oil Drilling \& Production Technology, 2011,33(4):71-74

14. Luo Tianyu,Jia Haizheng,Xu Jiangwen,Application of secondary sand fracturing technology in baikouquan formation glutenite in mabei sag[J], Sino-Global Energy, 2014,19(7) :48-52

15. W ang Yubin, Liu Jianwei ,Research and practice of secondary sandfrac fracturing technioue, Drilling and Production, 2005,27(5):81-87

16. Liu Liming, Guo Jianchun, Lu Cong et al. Application for secondary sand fracturing technology in well fan134-1, fan131 block[J]. Petroleum Geology and Recovery Efficiency,2014,21(1):107-110

17. LI Yong-ming, Li Lian-ming, Guo Jian-chun, Zhao Jin-zhou, Theoretical model and application of secondary sand fracturing[J], XinJiang Petroleum Geology,2010,31(2)190-193

18. Chen Huayong, Wang Zhiqiang, Tang Jianhong, Zhang Lu, Deng Ge. Application of fracture pressure prediction by secondary sand fracturing $[\mathrm{J}]$, World Well Logging 
Technology,2015,209(5) :34-37

19. An Fengjun,Zhao Anjun,Zhou Huizhi,Duan Guifu,Effect analysis of secondary sand fracturing using four-dimensional seisimic imaging of micro-fractrues[J], Petroleum Drilling Techniques, 2013,41(5):98-101

20. He Tao,Guo Jianchun,Lu Cong,Jing Yuquan,Optimization of Shut-in Time between the First and Second Fracturing by means of Pressure Decline Analysis[J], Petroleum Drilling Techniques,2015, 43(02): 110-115

21. Peter valko and michael J. Economides Hydraulic Fracture Mechanices(M),John Wiley \& Sons Ltd.1995:238-249

22. ZHAO Yanlin,CAO Ping,ZHAO Yangsheng,LIN Hang,Wang Yixian,Dual Media Model For Thermo-hydro-mechanical Coupling And 3D Numerical Simulation, Chinese Journal of Rock Mechanics and Engineering,2007,26(supplement 2)

23. Wang Hongxun,Zhang Shicheng, Numerical Techniques Method of Hydraulic Fracturing Design[M], Petroleum Industry Press,1998.6,238-242

24. Deng Jingen,Chen Yuanfang,Chen Mian,Wei Baohua, Wellbore stability technology[M], Petroleum Industry Press,2008,4:9-10 